\title{
Effect of sintering temperature on the structural properties of $\mathrm{La}_{0.7} \mathrm{Sr}_{0.25} \mathrm{Nd}_{0.05} \mathrm{MnO}_{3}$
}

\author{
$1^{\text {st }}$ D.S. Razaq ${ }^{1}, 2^{\text {nd }}$ D.R. Munazat ${ }^{1}, 3^{\text {rd }}$ Bambang Soegijono $^{1}, 4^{\text {th }}$ Budhy Kurniawan $^{*}, 5^{\text {th }}$ S. \\ Budiawanti ${ }^{2}, 6^{\text {th }}$ Dwi Nanto ${ }^{3}$ \\ \{bkuru@fisika.ui.ac.id,dwi.nanto@uinjkt.ac.id\} \\ Universitas Indonesia, Department of Physics, Depok 16424, Indonesia ${ }^{1}$, Sebelas Maret University, \\ Faculty of Teacher Training and Education, Solo 57126, Indonesia ${ }^{2}$, UIN Syarif Hidayatullah, \\ Department of Physics Education, Jakarta 15412, Indonesia ${ }^{3}$
}

\begin{abstract}
Crystalline structure of La0.7Sr0.25Nd0.05MnO3 (LSMNO) manganite have been investigated in order to study the effect of various sintering temperature. A series of LSMNO samples were prepared by citrate-nitrate sol-gel method followed by various sintering temperature at $700 \mathrm{oC}, 800 \mathrm{oC}$, and $900 \mathrm{oC}$. The crystalline structure of the samples was investigated by using X-ray diffractometer (XRD). The XRD patterns obtained were then analyzed by means of Rietveld refinement method. According to the XRD results there was no secondary phase found in all samples. Furthermore, refinement process show that all samples crystallize with rhombohedral symmetry within the space group of $\mathrm{R} 3 \overline{\mathrm{c}}$ regardless the applied various sintering temperature. Further crystallographic study reveals that average $\mathrm{Mn}-\mathrm{O}$ bond length increases meanwhile average $\mathrm{Mn}-\mathrm{O}-\mathrm{Mn}$ bond length decreases as sintering temperature were increased. To confirm chemical composition of LSMNO samples, we use X-ray fluorescence (XRF). $\mathrm{XRF}$ result reveal that all samples support stoichiometry design.
\end{abstract}

Keywords: Perovskite manganite; Sintering Temperature; Structure;

\section{Introduction}

Perovskite manganite with general formula $\mathrm{La}_{1-x} A_{x} \mathrm{MnO}_{3}\left(A=\mathrm{Ca}^{2+}, \mathrm{Ba}^{2+}, \mathrm{Sr}^{2+}, \mathrm{Nd}^{3+}, \mathrm{Na}^{+}\right.$, etc.) still remain to be one of the attractive material to be studied because its unique physical phenomenon such as colossal magnetoresistance (CMR) and magnetocaloric effect (MCE) [1, 2]. Furthermore, MCE phenomenon holds a massive importance to the development of renewable energy source especially to replace conventional refrigerator with magnetic refrigerator technology. During the last decade, modification to lanthanum based manganite have already advanced even further. One of the example of the advanced modification is by introducing more than one dopant on the $A$-site of the perovskite material [2-4]. When two ion will be doped into a modified perovskite manganite, an important thing to be considered is the physical properties of the basis material which have been selected. One of the example from the advanced modification in the lanthanum manganite is $\left(\mathrm{La}_{1-x} \mathrm{Nd}_{x}\right)_{0.7} \mathrm{Sr}_{0.3} \mathrm{MnO}_{3}$ manganite [4]. In this material, the basis material chosen was $\mathrm{La}_{0.7} \mathrm{Sr}_{0.3} \mathrm{MnO}_{3}$. Earlier study on this material by some researchers reveals that $\mathrm{La}_{0.7} \mathrm{Sr}_{0.3} \mathrm{MnO}_{3}$ has a high Curie temperature with low resistivity [5]. These two evident inspire other researchers to tune the physical phenomenon of $\mathrm{La}_{0.7} \mathrm{Sr}_{0.3} \mathrm{MnO}_{3}$ according to what the material will be applied to. By 
introducing neodymium to $\mathrm{La}_{0.7} \mathrm{Sr}_{0.3} \mathrm{MnO}_{3}$, it has been proven that Curie temperature of $\left(\mathrm{La}_{1}\right.$ $\left.{ }_{x} \mathrm{Nd}_{x}\right)_{0.7} \mathrm{Sr}_{0.3} \mathrm{MnO}_{3}$ decreases as the neodymium content increased [2, 4]. Furthermore, resistivity also increase when higher neodymium content was introduced to the material $[2,4]$.

$\mathrm{La}_{1-x-y} \mathrm{Sr}_{x} \mathrm{Nd}_{y} \mathrm{MnO}_{3}$ is an interesting among perovskite manganite material because its physical phenomenon can be tuned by varying strontium content and neodymium content. Despite its interesting physical phenomenon, study regarding physical phenomenon of $\mathrm{La}_{1-x}$ ${ }_{y} \mathrm{Sr}_{x} \mathrm{Nd}_{y} \mathrm{MnO}_{3}$ material still scanty. Thus, in this research perovskite manganite with chemical formula $\mathrm{La}_{0.7} \mathrm{Sr}_{0.25} \mathrm{Nd}_{0.05} \mathrm{MnO}_{3}$ will be studied mainly to understand the effect of sintering temperature used during synthesis on its crystalline structure. Although some researches have been conducted to study the effect of sintering on the structure or even to the physical properties from perovskite manganite, its effect on the crystal structure still a matter to be discussed [6,7]. Furthermore, this study is essential because previous work have already proved that sintering process plays a major role on the physical properties of ceramic compounds [8].

\section{Experiments}

Three different samples of $\mathrm{La}_{0.7} \mathrm{Sr}_{0.25} \mathrm{Nd}_{0.05} \mathrm{MnO}_{3}$ were prepared using citrate-nitrate solgel method. Stoichiometric amount of $\operatorname{Sr}\left(\mathrm{NO}_{3}\right)_{2}, \mathrm{Mn}\left(\mathrm{NO}_{3}\right)_{2} \cdot 4 \mathrm{H}_{2} \mathrm{O}$, and $\mathrm{C}_{6} \mathrm{H}_{8} \mathrm{O}_{7}$ (citric acid) were weighed and dissolved in double distilled water. The amount of citric acid that were used can be calculated using molar ratio of all metal ion to citric acid in $1: 1.2$ [9]. Precursors that were in oxide form such as $\mathrm{La}_{2} \mathrm{O}_{3}$ and $\mathrm{Nd}_{2} \mathrm{O}_{3}$ were diluted in nitric acid to convert metal oxide form into metal nitrate form following a chemical reaction

$$
M_{2} \mathrm{O}_{3}+6 \mathrm{HNO}_{3} \rightarrow 2 \mathrm{M}\left(\mathrm{NO}_{3}\right)_{3}+\mathrm{H}_{2} \mathrm{O}
$$

Where $M$ is metal ion, in this particular case are lanthanum and neodymium. After all the precursor were diluted in double distilled, then all the precursor were mixed together followed by a constant stirring using spin bar on a magnetic hotplate. Shortly,the fine powder then sintered at three different temperature which are $700{ }^{\circ} \mathrm{C}, 800{ }^{\circ} \mathrm{C}$, and $900{ }^{\circ} \mathrm{C}$. After sintering process was done, all samples are characterized using XRD to study its phase purity and crystal structure with step size of $0.02 \theta$ and scan rate more than one second for each step. Lastly, XRF measurement was carried out to ensure the stoichiometry of the samples. 

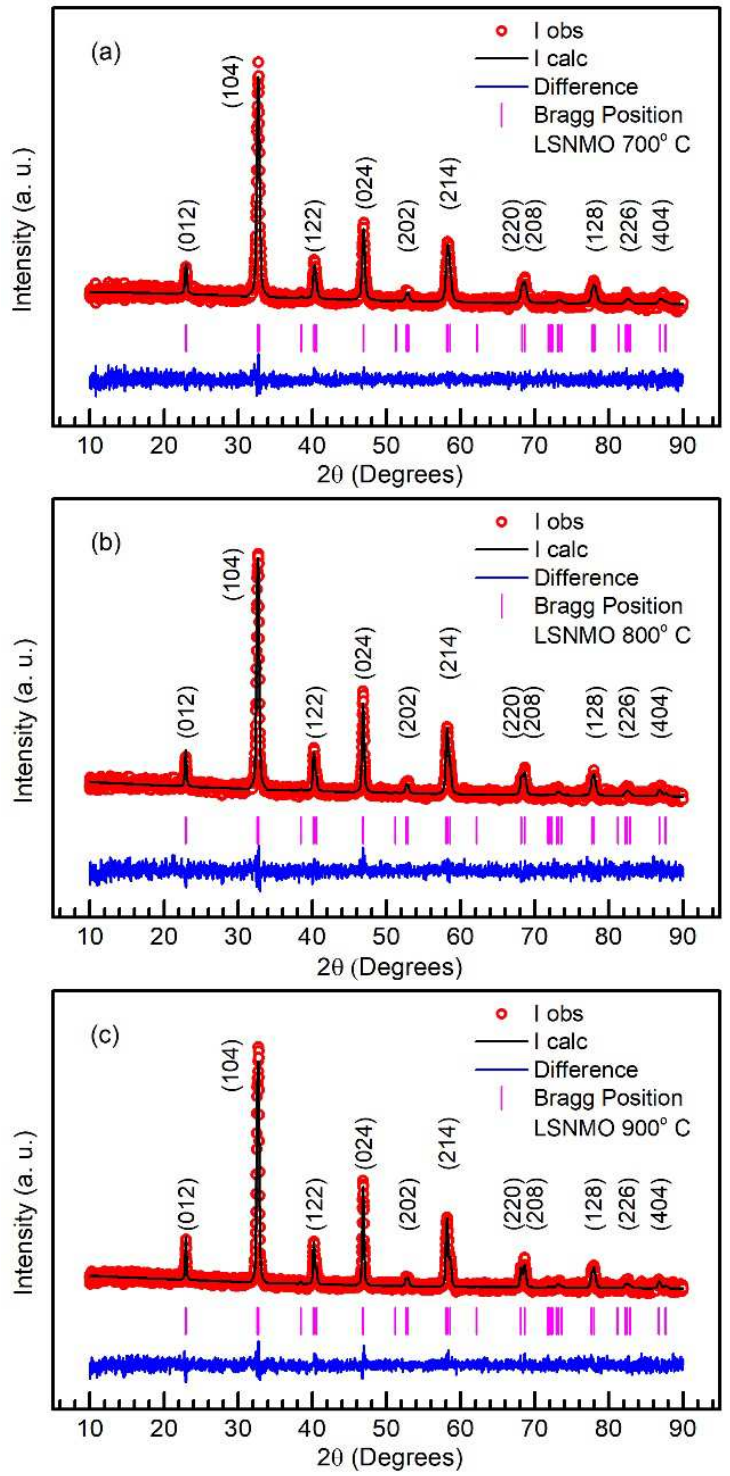

Figure 1. Powder XRD patterns include Rietveld refinement for $\mathrm{La}_{0.7} \mathrm{Sr}_{0.25} \mathrm{Nd}_{0.05} \mathrm{MnO}_{3}$ sintered at (a) $700{ }^{\circ} \mathrm{C}$, (b) $800{ }^{\circ} \mathrm{C}$, and (c) $900{ }^{\circ} \mathrm{C}$.

\section{Result and Discussion}

The crystal structure of each sample sintered at $700{ }^{\circ} \mathrm{C}, 800{ }^{\circ} \mathrm{C}$, and $900{ }^{\circ} \mathrm{C}$ was investigated by X-ray powder diffraction. The diffraction pattern obtained were then analyzed 
using Rietveld refinement and depicted in figure 1. Based on the miller indices of all the samples, it can be seen that all samples crystalline in rhombohedral structure with $\mathrm{R} \overline{3} \mathrm{c}$ space group regardless of the sintering temperature. This result met an agreement with several earlier study that have proven various sintering temperature does not affect crystalline structure of the sample $[6,10]$. From figure 1 , it can be seen that all sample have achieved a single phase state without any trace of impurities. This is proven as there are no diffraction peaks that were not matching with the database when observed diffraction pattern were compared to calculated pattern. The crystalline structural properties obtained using Rietveld refinement process detail explored on table 1.

The fitting process that compare observed diffraction pattern with database was good. This argument is supported with GOF value that close to unity and small Rwp and Rp value. There are almost no significant change in $c$-lattice parameter while there are a slight increasing trend in $a$-lattice parameter and $b$-lattice parameter. This change affect the unit cell volume which increase as sintering temperature increase. Similar result also reported by Oumezzine et. al when lanthanum manganite based sample were sintered at different temperature [6].

According to XRD pattern inspection, it can be seen that width of each diffraction peaks became narrower as sintering temperature increase. It will affect the average crystallite size of sample $\mathrm{La}_{0.7} \mathrm{Sr}_{0.25} \mathrm{Nd}_{0.05} \mathrm{MnO}_{3}$. We calculated the average crystallite size by using Scherrer equation.

$$
D_{S G}=\frac{0.9 \lambda}{\beta_{h k l} \cos \theta}
$$

Where $\lambda$ is $\mathrm{Cu} K \alpha$ wavelength (1.5406 $\AA$ ), $\theta$ is the diffraction angle, and $\beta_{h k l}$ is the full width at half-maximum (FWHM) of each diffraction peaks in radian. As sintering temperature increase, the average crystallite size also increase. This is a well-known phenomenon that happened when ceramic material is synthesized in various temperature. Similar result also reported the same phenomenon when ceramic material was sintered at different temperature $[8,10]$.

Table I. Refined structural parameter of $\mathrm{La}_{0.7} \mathrm{Sr}_{0.25} \mathrm{Nd}_{0.05} \mathrm{MnO}_{3}$ after refinement process using Rietveld refinement

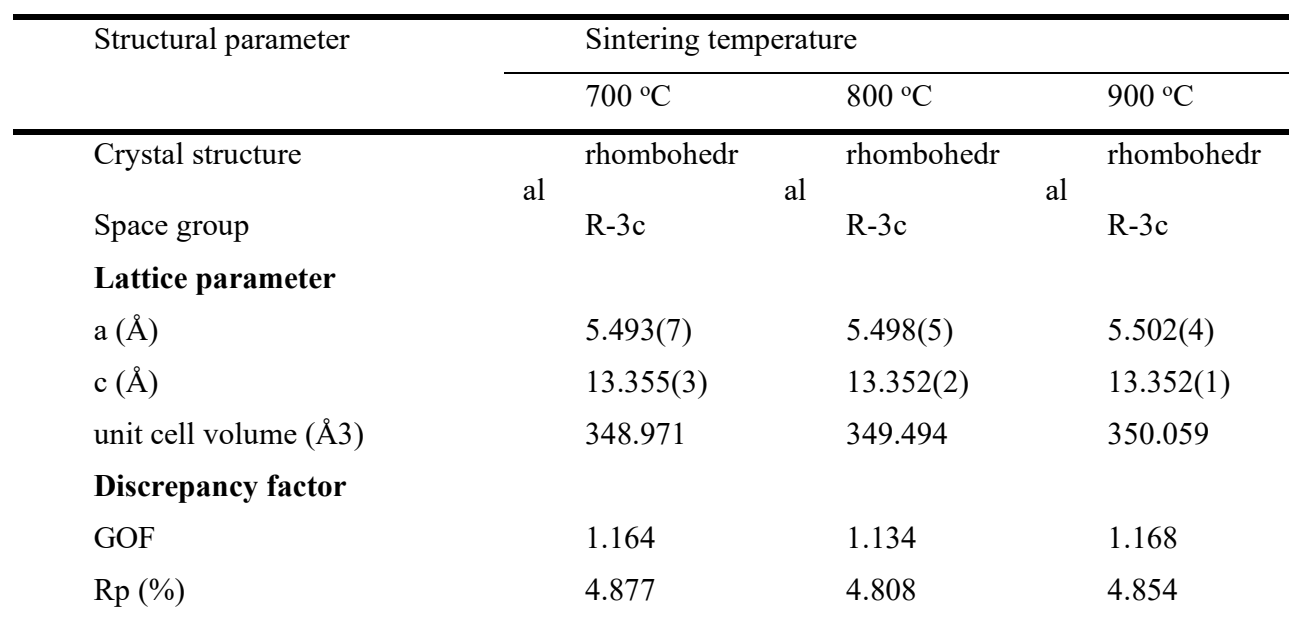


Rwp (\%)

Average crystallite size (nm)

$d_{<M n-a \gg}(\AA)$

$<\boldsymbol{M n}-\boldsymbol{o}-\boldsymbol{M n}>$ (degree)
6.135

19.719

1.952

165.777
6.012

27.504

1.953

165.772
6.122

36.155

1.954

165.768

Based on table 1, the average bond angle and average bond length of the samples are changing despite the same chemical composition. Reduction in average $\mathrm{Mn}-\mathrm{O}$ bond length $\left(d_{\text {Mn-O }}\right)$ and increasing value of average Mn-O-Mn bond angle $(\langle M n-O-M n\rangle)$ which observed in the sample is an indication that there are a distortion in the crystal structure of the sample. It has been known that an ideal perovskite structure is a cubic structure. Distortion can happen to a perovskite cubic structure which will distort the structure into a more unstable structure like rhombohedral and orthorhombic. The distortion usually happened when the average bond length is increasing while the average bond angle is decreasing compared to ideal cubic structure. In this particular study, the change in average bond angle and average bond length can be addressed to the interplay of the sintering temperature. Based on table 2 , it can be seen that higher temperature will distort the crystalline structure to a more unstable structure. This is due to the thermal energy that the sample received during manufacturing process of all the samples. Previous work already shown that change in average bond length and average bond angle will induce a change in the physical properties of the samples [11]. Thus, it can be predicted that different sintering temperature will cause a different physical properties of $\mathrm{La}_{0.7} \mathrm{Sr}_{0.25} \mathrm{Nd}_{0.05} \mathrm{MnO}_{3}$.

The stoichiometry of the samples synthesized was examined using X-ray fluorescence measurement. Figure 2 shows all the metal spectra which have been detected during XRF measurement. From figure 2, it can be seen that there are no significant difference in the XRF spectra of the three samples which synthesized with different temperature. this result is logical because from chemical point of view, sintering temperature does not change chemical composition. Thus, the XRF spectra of the three samples does not vary significantly. This results supports previous claim that all samples have achieved single-phase state without any trace of impurities.

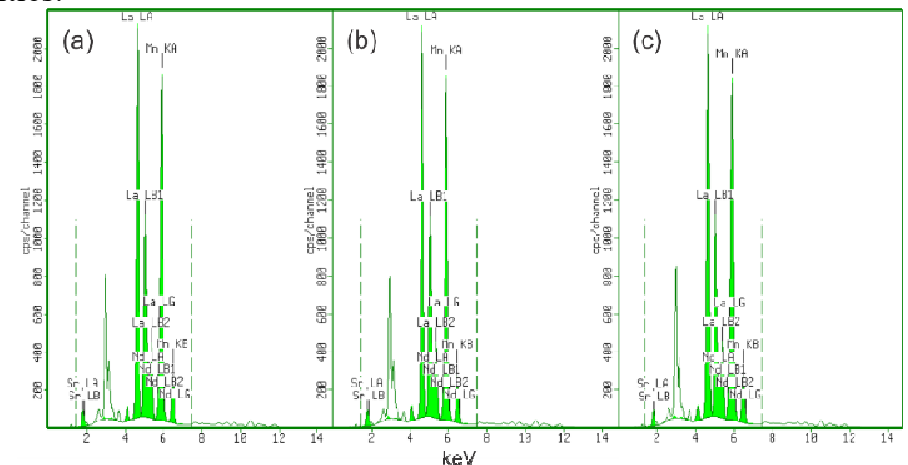

Figure 2. XRF result reveal that three different sample of $\mathrm{La}_{0.7} \mathrm{Sr}_{0.25} \mathrm{Nd}_{0.05} \mathrm{MnO}_{3}$ sintered at different temperature produce the same spectrum without any sign of impurities

Table 2 compares the metal concentration detected from XRF measurement with calculated value which have been calculated by stoichiometry approach. Difference in calculated value compared to measured value suggest that the samples studied in this research 
does not perfectly follow chemical stoichiometry value. This is due to the solution method which have been used to synthesize the samples. There are possibility that there exist a small amount of metal component left in one of the precursor's container as it is nearly impossible to pour all the precursor perfectly in solution form to the reaction glass.

Table 2. Metal content in each sample from XRF result compared with calculation based on stoichiometry process

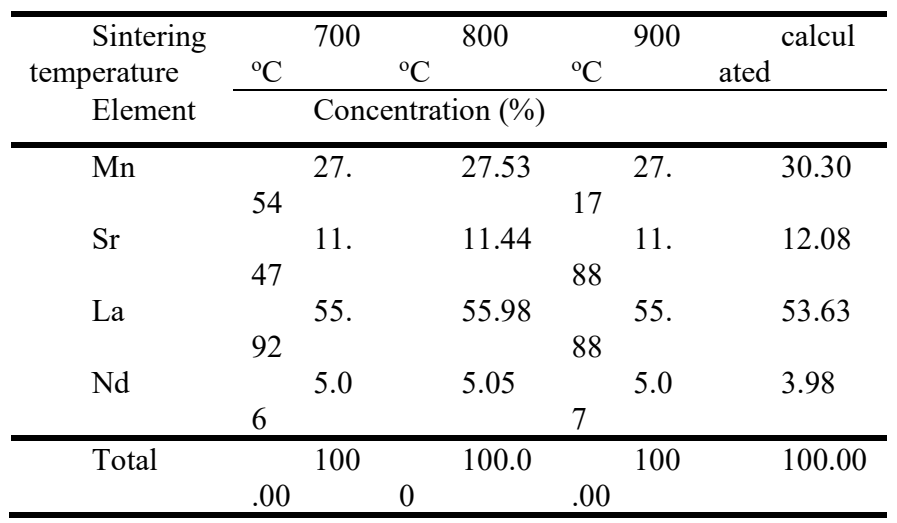

\section{Conclusion}

In this research, doped lanthanum manganite system with chemical formula $\mathrm{La}_{0.7} \mathrm{Sr}_{0.25} \mathrm{Nd}_{0.05} \mathrm{MnO}_{3}$ have been studied mainly to study sintering temperature effect on its crystal structure. Three samples which have been synthesized using citrate-nitrate sol-gel method and sintered with different temperature does not show any trace of impurities. It has been shown that sintering does not affect the crystal structure of $\mathrm{La}_{0.7} \mathrm{Sr}_{0.25} \mathrm{Nd}_{0.05} \mathrm{MnO}_{3}$ which remain in the rhombohedral structure with $\mathrm{R}^{\overline{3}} \mathrm{c}$ space group. Evidently, it has been shown that sintering temperature enlarge the unit cell volume of the same sample. Moreover, sintering temperature distorts the bond length and bond angle of $\mathrm{La}_{0.7} \mathrm{Sr}_{0.25} \mathrm{Nd}_{0.05} \mathrm{MnO}_{3}$. As commonly seen in other ceramic material, sintering effect increase the average crystallite size of $\mathrm{La}_{0.7} \mathrm{Sr}_{0.25} \mathrm{Nd}_{0.05} \mathrm{MnO}_{3}$. XRF spectra result shows that the sample which have been synthesized does not perfectly follow the chemical formula.

Acknowledgements. This paper in conjuction with the 1st International Conference on Islam, Science and Technology (ICONIST) 2018

\section{References}

[1] A. Rostamnejadi, M. Venkatesan, P. Kameli, H. Salamati, and J. M. D. Coey, "Magnetocaloric effect in $\mathrm{La}_{0.67} \mathrm{Sr}_{0.33} \mathrm{MnO}_{3}$ manganite above room temperature," Journal of Magnetism and Magnetic Materials, vol. 323, no. 16, pp. 2214-2218, Aug. 2011.

[2] H. Qin, J. Hu, J. Chen, L. Zhu, and H. Niu, "The Nd Doping Effect on the Room Temperature 
Magnetoresistance in Manganites $\left(\mathrm{La}_{1-x} \mathrm{Nd}_{x}\right)_{0.67} \mathrm{Sr}_{0.33} \mathrm{MnO}_{3} \quad(x \leq \quad 0.3)$, , MATERIALS TRANSACTIONS, vol. 45, no. 4, pp. 1251-1254, 2004.

[3] K. Cherif, S. Zemni, J. Dhahri, J. Dhahri, M. Oumezzine, M. Ghedira, and H. Vincent, "Magnetocaloric effect in the doped perovskite manganese oxide $\mathrm{La}_{0.7-x} \mathrm{Nd}_{x} \mathrm{Sr}_{0.3} \mathrm{MnO}_{3}(x=0.42,0.56$ and 0.7)," Journal of Alloys and Compounds, vol. 396, no. 1-2, pp. 29-33, Jun. 2005.

[4] K. Cherif, J. Dhahri, E. Dhahri, M. Oumezzine, and H. Vincent, "Effect of the A Cation Size on the Structural, Magnetic, and Electrical Properties of Perovskites $\left(\mathrm{La}_{1-x} \mathrm{Nd}_{x}\right)_{0.7} \mathrm{Sr}_{0.3 \mathrm{r} 003 \mathrm{nMnO}}$," Journal of Solid State Chemistry, vol. 163, no. 2, pp. 466-471, Feb. 2002.

[5] T. L. Phan, N. Van Khiem, J. Zidanic, Nguyen Xuan Phuc, and Seong-Cho Yu, "Influence of asite substitution on the EPR parameters of $\mathrm{La} / \mathrm{sub} 0.7 / \mathrm{A}^{\prime} / \mathrm{sub} 0.3 / \mathrm{MnO} / \mathrm{sub} 3 /(\mathrm{A}$ '= $\mathrm{Sr}, \mathrm{Ba})$ compounds," IEEE Transactions on Magnetics, vol 41, no. 10, pp 2769 to 2771, Oct 2005

[6] M. Oumezzine, O. Peña, T. Guizouarn, R. Lebullenger, and M. Oumezzine, "Impact of the sintering temperature on the structural, magnetic and electrical transport properties of doped $\mathrm{La}_{0,67} \mathrm{Ba}_{0,33} \mathrm{Mn}_{0,9} \mathrm{Cr}_{0,1} \mathrm{O}_{3}$ manganite," Journal of Magnetism and Magnetic Materials, vol. 324, no. 18, pp. 2821-2828, Sep. 2012.

[7] Y. Kalyana Lakshmi and P. Venugopal Reddy, "Influence of sintering temperature and oxygen stoichiometry on electrical transport properties of $\mathrm{La} 0.67 \mathrm{Na} 0.33 \mathrm{MnO}_{3}$ manganite," Journal of Alloys and Compounds, vol. 470, no. 1-2, pp. 67-74, Feb. 2009.

[8] S. Othmani, M. Bejar, E. Dhahri, and E. K. Hlil, "The effect of the annealing temperature on the structural and magnetic properties of the manganites compounds," Journal of Alloys and Compounds, vol. 475, no. 1-2, pp. 46-50, May 2009.

[9] Y. Li, L. Xue, L. Fan, and Y. Yan, "The effect of citric acid to metal nitrates molar ratio on solgel combustion synthesis of nanocrystalline LaMnO3 powders," Journal of Alloys and Compounds, vol. 478, no. 1-2, pp. 493-497, Jun. 2009.

[10] H. Baaziz, N. K. Maaloul, A. Tozri, H. Rahmouni, S. Mizouri, K. Khirouni, and E. Dhahri, "Effect of sintering temperature and grain size on the electrical transport properties of La0.67 $\mathrm{Sr}_{0.33} \mathrm{MnO}_{3}$ manganite," Chemical Physics Letters, vol. 640, pp. 77-81, Nov. 2015.

[11] P. G. Radaelli, G. Iannone, M. Marezio, H. Y. Hwang, S.-W. Cheong, J. D. Jorgensen, and D. N. Argyriou, "Structural effects on the magnetic and transport properties of perovskite ${ }_{1-x} \mathrm{Ax}^{\prime} \mathrm{MnO}_{3}(x=0.25,0.30)$," Physical Review B, vol. 56, no. 13, pp. 8265-8276, Oct. 1997. 